\title{
Seed Quality and Protein Classification of Some Quinoa Varieties
}

\author{
Ahmed F. Abd El-Hakim*, Emad Mady ${ }^{2,3}$, Ayman M. Abou Tahoun4, \\ Mohammed S.A. Ghaly ${ }^{1}$, Mohamed A. Eissa ${ }^{5}$ \\ 1 Biochemistry Department, Faculty of Agriculture, Al-Azhar University, Nasr City, Cairo, Egypt \\ 2 Environmental Conservation Department, University of Massachusetts, Amherst, USA \\ ${ }^{3}$ Horticulture Department, Faculty of Agriculture, Al-Azhar University, Nasr City, Cairo, Egypt \\ ${ }^{4}$ Agronomy Department, Faculty of Agriculture, Al-Azhar University, Nasr City, Cairo, Egypt \\ ${ }^{5}$ Biotechnology Department, Faculty of Agriculture, Al-Azhar University, Nasr City, Cairo, Egypt \\ * Corresponding author: ahmedgyn@azhar.edu.eg
}

\begin{abstract}
Quinoa plants, originating from the Andean mountains in South America, have a large scale of biological diversity. Along with the cultivation favorableness of quinoa, it reveals superior nutrition aspects. In comparison with cereal crops, like rice, maize, and wheat, quinoa seeds contain valuable quantities of protein of remarkable quality. The current study compared four quinoa cultivars from different origins in terms of protein composition and germinability. In addition, this study focused on the effect of different geographical cultivation areas on the protein composition of wild Egyptian quinoa seeds and three other cultivars that vary in their cultivation origins. Significant differences were observed among the quinoa varieties in the germination percentage (GP), shoot length (SL), and root length (RL). Using the technology of Near-InfraRed Spectroscopy, the highest protein value was recorded for the American variety (18.39\%), followed by the Wild Egyptian variety (17.16\%). The aromatic phenylalanine recorded the highest concentration of the essential amino acid bulk. The Rainbow variety contained $12.7 \mathrm{~g}$-aa $/ \mathrm{kg}$ protein, followed by the wild Egyptian variety with $4.9 \mathrm{~g}$-aa/ $\mathrm{kg}$ protein. In turn, glutamic was the most abundant amino acid of the non-essential amino acids, with 10.1, 4, 23.4, and 4 (g-aa/kg protein) for quinoa varieties, Wild Egyptian, American, Rainbow, Black, respectively. SDS-PAGE was used to identify the allelic variations in the seed storage protein profiles among the studied quinoa varieties. The studied quinoa varieties showed $23.81 \%$ of the polymorphism in the protein bands, with the mean band frequency of 0.881 . The resulting protein bands fluctuated in the range between 115.02 and $16 \mathrm{kDa}$. With a similarity percentage (90\%), Wild Egyptian and the Rainbow quinoa varieties can be classified in one clade.
\end{abstract}

Keywords: Quinoa; seed vigor; seed quality; amino acids composition; various agro-climatic zones.

\section{INTRODUCTION}

The quinoa plant, Chenopodium quinoa Willd, originates mainly from South America, the Andean region (Angeli et al. 2020). It has a large scale of biological diversity, which implies differences in the morphological, biochemical, and genetic makeup. Meanwhile, the quinoa plant belongs to the Chenopodiaceae family. Moreover, the Chenopodium genus comprises about 250 species worldwide (Vega-Gálvez et al. 2010a).

Quinoa, a pseudo-cereal crop, has a high potential for non-preferable cultivation conditions.
In addition, the ability of the quinoa plant to adapt to salinity and drought conditions enables it to grow under a wide range of environmentalclimate statuses, promoting this crop to spread worldwide (Al-Naggar et al. 2017; Roman et al. 2020; Qureshi and Daba 2020). The quality of every seed depends on the genetic, physical, physiological, and hygienic characteristics of the seed (Santos et al. 2007). In addition, the environmental conditions, such as temperature and relative humidity, affect the rate of germination. The porosity of quinoa seeds causes a loss of viability more rapidly than cereals (Spehar 2007). 
The poor germination rate affects the quality and vitality of the quinoa seed which is reflected in the germination percentage (Kappes et al. 2012).

On the other hand, the quinoa plant, along with the cultivation favorableness, has superior nutrition aspects. In the case of limited resources for traditional crops, quinoa is considered an ideal nutritional alternative. The most economical part of the quinoa plant is the seed due to its nutritive values of carbohydrates, proteins, fats, fibers, and mineral substances such as calcium, potassium, and zinc (Alvarez-Jubete et al. 2009; Sobota et al. 2020). In comparison with cereal crops, like rice, maize, and wheat, quinoa seeds contain valuable quantities of protein contents of incredible quality. Hence, quinoa includes most of the essential amino acids, with a composition that is adequate to the adults' requirements. For instance, quinoa proteins have significantly high quantities of the amino acids' lysine and threonine, 7.8 and $8.9 \mathrm{~g} / 100 \mathrm{~g}$ protein, respectively (Vilcacundo and Hernández-Ledesma 2017). Moreover, quinoa seeds demonstrated a higher quality index than conventional cereals, as defined by the tryptophan percentage of the total protein (Gonzalez et al., 2012; Nowak et al. 2016). In addition, it is a good choice for those sensitive to gluten food, celiac disease patients (Galindo-Luján et al. 2021a). Furthermore, quinoa seeds are a rich food in vitamins and antioxidant compounds. Compared to wheat and barley, quinoa grains exhibited a higher content of superoxide dismutase and tocopherol isomers (Granda et al. 2018). Many polyphenolic compounds such as flavonoids, including quercetin, kaempferol, vanillic acid and their derivatives, ferulic acid and their glycosides, in addition to anthocyanins or betacyanin, were found as the functional antioxidant compounds of quinoa seeds (Abderrahim et al. 2015).

Considering the growing interest in quinoa cultivation and its popularity in the domestic and international markets, there is a deficit of scientific literature about the physiological quality of quinoa grains; thus, the current study aimed to evaluate the effect of various agro-climatic zones on seed germination attributes. In addition, the current study highlighted the effect of quinoa cultivation in various geographical areas on the protein composition of wild Egyptian seeds and three other imported cultivars that vary in their cultivation origins.

\section{MATERIALS AND METHODS}

\section{Plant material}

In the present study, four varieties of quinoa, including Egyptian, American, Rainbow, and Black, were used (Table 1). The seeds of Wild Egyptian variety were collected locally and maintained by the Faculty of Agriculture, Al-Azhar University, Egypt. While the American and Rainbow seeds were imported by the Central Laboratory of Organic Agriculture (CLOA), Agricultural Research Center (ARC), Giza, Egypt, whereas, the Black quinoa seeds were purchased from Now Foods, Now Health Group, Inc (Bloomingdale, IL, USA).

\section{Germination experiment}

The germination study was carried out in 2019 at the Faculty of Agriculture, Al-Azhar University's Biochemistry Research Laboratory. Four duplicates were carried out under a totally random design. For surface sterilization of the seeds, about 20 minutes in 20 percent $(\mathrm{V} / \mathrm{v})$, the seeds were immersed in sodium hypochlorite. The seeds were then cleaned and submerged in the water of the distillation. In order to eliminate saponin from the seeds and to prevent microbial contamination during the germination period, the sterilizing procedure was necessary (Panuccio et al. 2014).

Petri plates were cleaned and washed with distilled water for the germination experiments, while the filter paper was autoclaved at a temperature of $120{ }^{\circ} \mathrm{C}$ to avoid contamination. In

Table 1. Origin and seed color of the studied quinoa species

\begin{tabular}{|c|c|c|c|c|}
\hline Variety & Wild Egyptian & American & Rainbow & Black \\
\hline Wild Egyptian & 100 & & & \\
\hline American & 81 & 100 & & \\
\hline Rainbow & 90 & 90 & 100 & 100 \\
\hline Black & 89.5 & 80 & 89.5 & \\
\hline
\end{tabular}


order to remove any damaged or deformed seeds, the seeds were checked and graded carefully. For each investigated variety, four replicates of 100 seeds were assessed. In Petri plates, the substrate was $10 \mathrm{~cm}$ in diameter in the germination test. In each platform four replicates of 50 seeds were performed in the usual germination test. After planting in the dark with a relative humidity of 70 percent, seeds were incubated for five days at a constant temperature of $23 \pm 1{ }^{\circ} \mathrm{C}$.

As a percentage of normal seedlings, the germination percentage (GP) was computed. From day two, the germinated seeds were counted daily, and the experiment was declared complete when no more radical protrusions were found within six days on average. The germinated seeds had a normal radicle and expanded to a minimum of $2 \mathrm{~mm}$ in addition to the normal shoot (Wu et al. 2020). The length of the sowing, at six days following sowing, was measured by means of a one-millimeter ruler using the shoot and primary root of 10 normal seedlings of each replicate. The data were subjected to a normality test, variance analysis, and response surface using the GENES software program (Cruz 2013).

\section{Estimation of the total seed storage protein}

Near-InfraRed (NIR) Spectroscopy equipment, model DA1650 (FOSS Co., Hilleroed, Denmark) was used to determine the total seed protein content for each of the investigated varieties in the Central Laboratory, Faculty of Agriculture, Al-Azhar University (Encina-Zelada et al. 2017; Rodríguez et al. 2019; Taha et al. 2016).

\section{The amino acid composition analysis}

A Sykam S 433 amino acid analyzer was used to determine the amino acid composition according to the AOAC method (Latimer Jr. 2016). In order to digest the samples for $24 \mathrm{~h}$, equal weights of the samples were treated with $25 \mathrm{ml}$ of $6 \mathrm{~N}$ $\mathrm{HCl}$. As soon as the digestion process was completed, the residual liquid fraction was dissolved in sodium citrate buffer, which included $0.02 \mathrm{~N}$ of $\mathrm{HCl}(\mathrm{pH} 2.2)$. A millipore $0.45 \mathrm{~m}$ membrane filter was used to filter one $\mathrm{ml}$ of the fluid for each sample. Standards of 18 amino acids were handled the same way as the tested samples. On a dry weight basis, the amino acid/protein (g-aa/ $\mathrm{kg}$ protein) ratio was used to represent the amino acid concentrations.

\section{SDS-PAGE analysis}

The Mini-Protean Electrophoresis Cell, manufactured by Bio-Rad Corporation (Hercules, CA, USA), was used to analyze the protein banding patterns according to Laemmli (1970). The gel was placed in the staining solution after electrophoresis and incubated overnight with a moderate shaking, as reported by Carpenter et al. (1996). As a further step, the gel was poured into the destaining solution and gently agitated for about $2 \mathrm{~h}$ before washing it many times with ddH2O until the protein bands appeared clearly on the gel.

\section{Analysis of protein banding patterns}

After the staining processes were completed, gels were checked on a white box. A digital camera with a resolution of 20 megapixels was used to capture a picture for each of the investigated protein banding patterns. UVIgeltec, a gel documentation system created by UVItec Cambridge Corporation, was used to examine the banding pattern of the protein gel pictures that were produced.

\section{Statistical analysis}

The protein gel was twice run for pattern verification, and either present $(+)$ or absent $(-)$ of the reproducible bands were graded. The similarity matrix generated between quinoa varieties was computed with the coefficient of Jaccard (Jaccard 1908). The samples were analyzed by NTSYS-PC2.1 software for cluster analysis using the method of UPGMA, Unweighted Pair Group with the Arithmetic Mean.

\section{RESULTS AND DISCUSSION}

\section{Germination percentage, shoot length and root length}

The germination percentage (GP), shoot length (SL), and root length (RL) of the studied quinoa varieties are displayed in Figure 1. The American and Wild Egyptian varieties showed a superior GP (76.33 and 78.67\%) over the Rainbow and Black quinoa varieties (68.67 and 64.67\%) (at $\mathrm{p}<0.05$ ), respectively. The Wild Egyptian and American varieties produced significantly longer SL and RL than the Rainbow and Black quinoa varieties. In general, the germination test results 


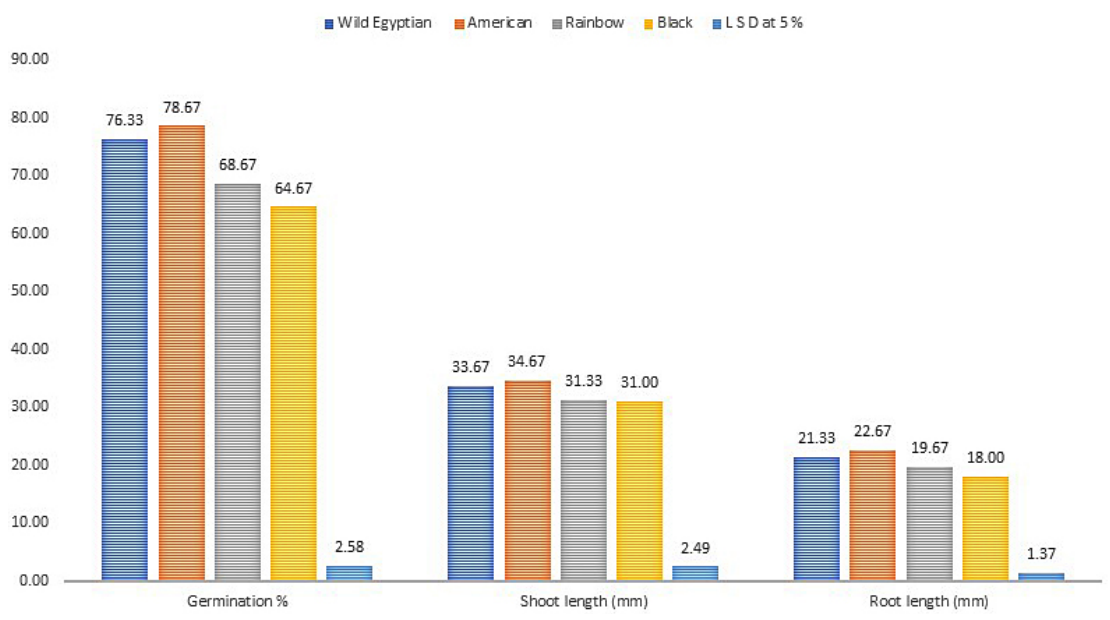

Figure 1. Germination percentage, shoot and root length $(\mathrm{mm})$ among the studied quinoa varieties

showed that the American and Wild Egyptian varieties of quinoa are more vigorous than the two other varieties, i.e., Rainbow and Black. Piñuel et al. 2019, reported the highest germination ratio at $28^{\circ} \mathrm{C}$ for the red quinoa after 72 hours by $46 \%$, while the white and black quinoa showed less germination under these conditions. Moreover, D'ambrosio et al. (2017) examined the germination of wild Chilean and Bolivian quinoa varieties and demonstrated the superiority of the Bolivian quinoa over the Chilean one after four days by 72 to $50 \%$, respectively.

In fact, the germination stage of the plant is a vital part of its existence that, in accordance with the environmental situation around each plant type, is genetically controlled. The process of germination involves two stages: one corresponds to water absorption, and the other includes metabolic reactions towards the emergence of a new plant (Sigstad and Prado 1999). Physiological and environmental variables combine to impact the germination of seeds. Each plant species has distinct germination requirements for water, temperature, and light suitability. For instance, water absorption by the seeds during the germination stage is hindered by the soil negativity potential in dry and semiarid areas with recurring adversities, like the situations of increased salinity and dehydration (dos Santos et al. 2016). In order to identify the vigor collection of seeds for the wide range of cultivation, seed tests are utilized to indicate variances resulting from the environmental and storage conditions (Filho 2015). In turn, germination and vigor tests are counterparts for examining the physiological state and seeds performance under a wide cultivation range. Meanwhile, vigor variability can be estimated via many tests, such as the speed index of germination and the potential of the emergence (Franzin et al. 2004). Therefore, examining the seed germination and their vigor is essential parameters for cultivation under different agro-climatic zones.

\section{The total seed storage protein}

The total seed storage proteins in each of the studied quinoa varieties were estimated using the technology of Near-Infra-Red Spectroscopy. The highest value was recorded for the American variety by $18.39 \%$, followed by the Wild Egyptian variety by $17.16 \%$. Then, the Rainbow variety had $16.27 \%$, while the Black variety contained the lowest value of seed storage protein $(12.83 \%)$ (Table 2$)$. These results agree

Table 2. Percentage of total seed storage protein for each of the studied Quinoa variety

\begin{tabular}{|c|c|}
\hline Variety & Total seed storage protein $\%$ \\
\hline Wild Egyptian & 17.16 \\
\hline American & 18.39 \\
\hline Rainbow & 16.27 \\
\hline Black & 12.83 \\
\hline
\end{tabular}

with previous reports on the protein content of quinoa species (Miranda et al. 2011; Nowak et al. 2016; Vega-Gálvez et al. 2010). In the meantime, the protein content in the grains of quinoa genotypes varied from 13.8 to $16.5 \%$, with an average of $15 \%$ dry matter, which surpasses the same contents in wheat (14.8\%) and barley (11.0\%) (Filho et al. 2017). 


\section{The amino acid composition analysis}

On a dry weight basis, the amino acid/protein ratio, $\mathrm{g} / \mathrm{kg}$ protein, was used as a rough measure of protein concentration. As shown in Table 3 a,b, and Figure 2, 3, the studied quinoa varieties showed reasonable concentrations of the essential amino acids for histidine, isoleucine, leucine, lysine, methionine, phenylalanine, threonine, and valine amino acids. The aromatic amino acid phenylalanine recorded the highest concentration of the essential amino acids bulk. However, the Rainbow variety contained 12.7 (g-aa/kg protein), followed by the wild Egyptian variety 4.9 (g-aa/ $\mathrm{kg}$ protein), then both of American and Black varieties which showed 3.6 and 3.7 (g-aa/kg protein), respectively. Furthermore, the limiting amino acids lysine was found to have the highest value in the wild Egyptian variety (1.8 g-aa/ $\mathrm{kg}$ protein) rather than the other varieties, which contained equal amounts of $1.3 \mathrm{~g}$-aa $/ \mathrm{kg}$ protein. Moreover, the concentration of the valuable amino acids, i.e., isoleucine, leucine, and methionine, were the highest values in the Rainbow variety $(6.6,3.7$, and $2.3 \mathrm{~g}$-aa $/ \mathrm{kg}$ protein, respectively) rather than the other three varieties.

Glutamic was the most abundant of the nonessential amino acids, with 10.1, 4.0, 23.4, and 4.0 (g-aa/ $\mathrm{kg}$ protein) in the seeds of the studied quinoa varieties, Wild Egyptian, American,

Table 3a. Essential amino acids (g-aa/kg protein) in the studied quinoa varieties.

\begin{tabular}{|c|c|c|c|c|}
\hline \multicolumn{2}{|c}{ Amino Acids } & American & Rainbow & Black \\
\hline Histidine & 0.9 & 0.6 & 2.1 & 0.6 \\
\hline Iso-Leucine & 2.7 & 1.8 & 6.6 & 1.8 \\
\hline Leucine & 1.3 & 0.9 & 3.7 & 0.9 \\
\hline Lysine & 1.8 & 1.3 & 1.3 & 1.3 \\
\hline Methionine & 0.7 & 0.4 & 2.3 & 0.4 \\
\hline Phenylalanine & 4.9 & 3.6 & 12.7 & 3.7 \\
\hline Threonine & 1 & 0.5 & 8.8 & 0.5 \\
\hline Valine & 1 & 0.3 & 2.3 & 0.3 \\
\hline
\end{tabular}

Table 3b. Non-essential amino acids ( $\mathrm{g}$-aa/kg protein) in the studied quinoa varieties.

\begin{tabular}{|c|c|c|c|c|}
\hline Amino Acids & Wild Egyptian & American & Rainbow & Black \\
\hline Aspartic & 5.3 & 1.3 & 7.1 & 1.3 \\
\hline Serine & 2.2 & 0.8 & 8 & 0.8 \\
\hline Glutamic & 10.1 & 4 & 23.4 & ND \\
\hline Proline & 0.9 & ND & ND & 1.6 \\
\hline Glycine & 2.3 & 1.6 & 5.4 & 1.8 \\
\hline Alanine & 2.4 & 1.8 & 2.6 & 1.1 \\
\hline Cystine & 2 & 1.1 & 0.6 & 0.3 \\
\hline Valine & 1 & 0.3 & 2.3 & \\
\hline
\end{tabular}

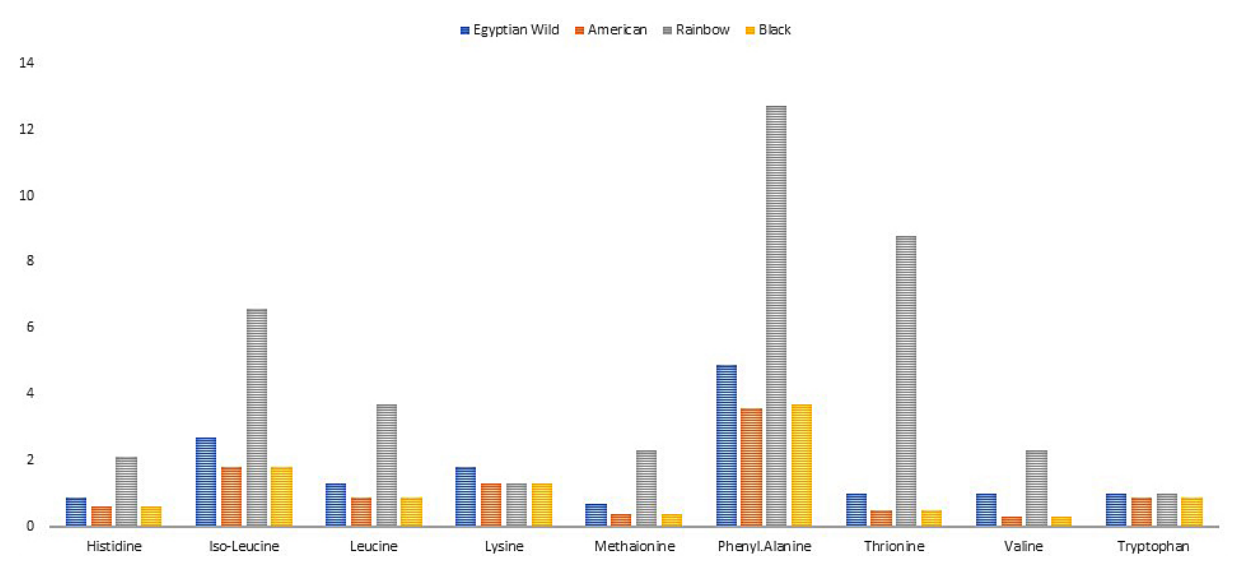

Figure 2. Essential Amino acids composition profile (g-aa/1 kg protein) 


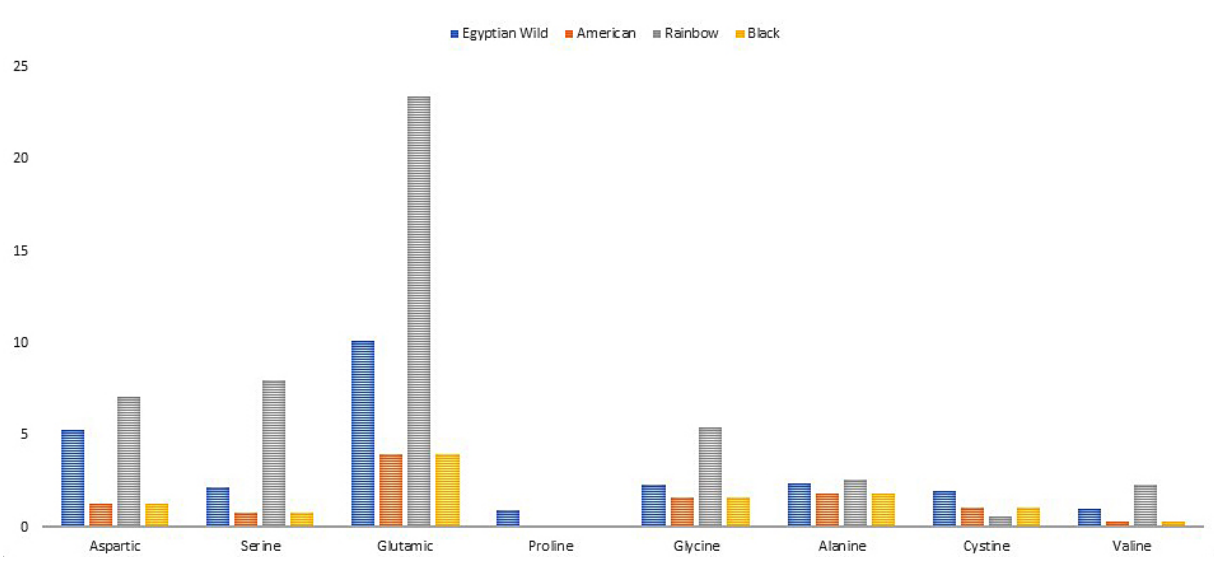

Figure 3. Non-essential amino acids composition profile (g-aa/1 kg protein)

Rainbow, Black, respectively. Then, the serine, aspartic, and glycine amino acids showed noticeable concentrations across the rest of the nonessential amino acids. Quinoa is a pseudocereal crop that was demonstrated as a rich source of high-quality protein (Mota et al. 2016; Nowak et al. 2016; Song et al. 2021). Craine and Murphy (2020) preferred the term "nearly complete protein" rather than the term "complete protein" due to the variation in amino acids composition, which can be differed upon both the population and the location of the cultivation. Meanwhile, González et al. (2012) deduced that both environmental and climatic factors affect the nutritional composition, including total protein content and the composition of amino acids of quinoa seeds in various agro-climatic zones.

\section{SDS-PAGE analysis and protein banding patterns}

Sodium dodecyl sulfate-polyacrylamide gel electrophoresis technique (SDS-PAGE) was used to identify the molecular variations in the seed storage protein among the studied quinoa varieties. As shown in Figure 4 and Table 4 a,b, the studied quinoa varieties indicated $23.81 \%$ of the polymorphism in the protein bands, with the mean band frequency of 0.881 . In the range between $115.02 \mathrm{kDa}$ to $16 \mathrm{kDa}$, the total number of bands was 21 , which included five polymorphic bands, two of which were unique. The Wild Egyptian variety had a unique band at the molecular weight of $40.07 \mathrm{kDa}$, while the American variety had a unique one at the molecular weight of $32.14 \mathrm{kDa}$. These unique bands can be considered positive markers. The other polymorphic bands were found at the molecular weights of $37.97 \mathrm{kDa}, 34.09 \mathrm{kDa}$, and $31.21 \mathrm{kDa}$. The polymorphic bands at $34.09 \mathrm{kDa}$ and $31.21 \mathrm{kDa}$ can be defined as negative markers for American and Black quinoa varieties, respectively. The $11 \mathrm{~s}$ and $2 \mathrm{~s}$ albumin subunits were previously described as the main constituents for the seed storage proteins of quinoa species (Brinegar and Goundan 1993). A range of four molecular weights, 23, 31, 35, and 52, characterized the quinoa species (Thanapornpoonpong et al. 2008).

In addition to the polymorphism of the protein bands, another variation type was found in the intensities of the matched bands. Hence, the wild Egyptian variety showed the highest densities in bands volumes, which was represented through the increase in the area under the curve

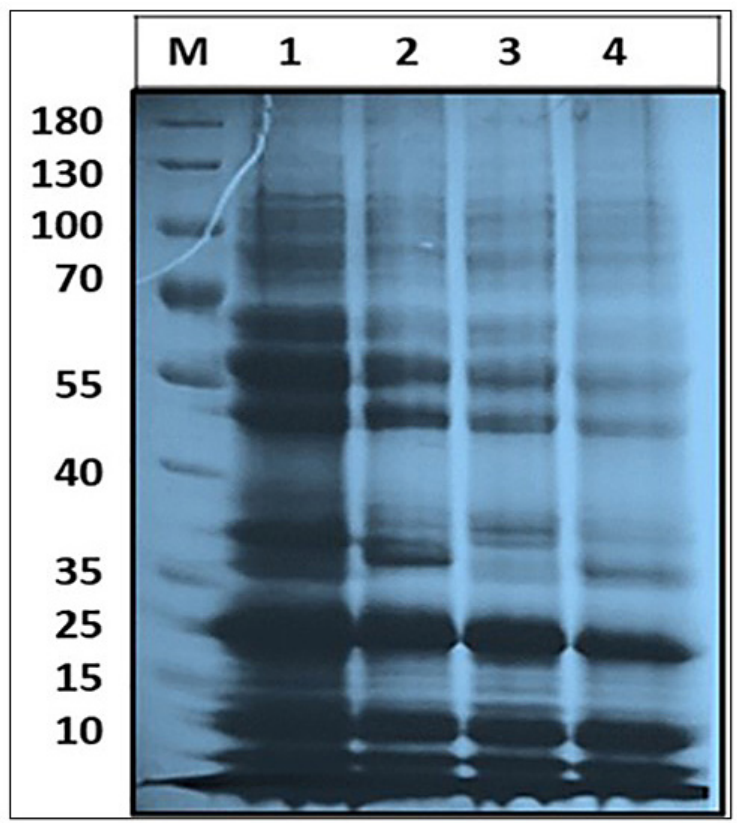

Figure 4. The SDS-PAGE protein electrophoresis gel for the studied quinoa varieties: WildEgyptian, American, Rainbow, Black 
Table 4.a. SDS-PAGE protein gel scoring sheet and the frequency of each band

\begin{tabular}{|c|c|c|c|c|c|c|c|}
\hline $\mathrm{RF}$ & MW kDa & Wild Egyptian & American & Rainbow & Black & Frequency & Polymorphism \\
\hline 0.130 & 115.022 & + & + & + & + & 1.00 & Monomorphic \\
\hline 0.155 & 108.183 & + & + & + & + & 1.00 & Monomorphic \\
\hline 0.176 & 102.754 & + & + & + & & 1.00 & Monomorphic \\
\hline 0.203 & 96.172 & + & + & + & + & 1.00 & Monomorphic \\
\hline 0.251 & 85.495 & + & + & + & + & 1.00 & Monomorphic \\
\hline 0.297 & 76.376 & + & + & + & + & 1.00 & Monomorphic \\
\hline 0.316 & 72.900 & + & + & + & + & 1.00 & Monomorphic \\
\hline 0.382 & 62.009 & + & + & + & + & 1.00 & Monomorphic \\
\hline 0.442 & 53.526 & + & + & + & + & 1.00 & Monomorphic \\
\hline 0.560 & 40.079 & + & - & - & - & 0.25 & Unique \\
\hline 0.582 & 37.974 & - & + & + & - & 0.50 & Polymorphic \\
\hline 0.601 & 36.246 & + & + & + & + & 1.00 & Monomorphic \\
\hline 0.626 & 34.091 & + & + & + & - & 0.75 & Polymorphic \\
\hline 0.650 & 32.143 & - & + & - & - & 0.25 & Unique \\
\hline 0.662 & 31.211 & + & - & + & + & 0.75 & Polymorphic \\
\hline 0.768 & 24.068 & + & + & + & + & 1.00 & Monomorphic \\
\hline 0.812 & 21.607 & + & + & + & + & 1.00 & Monomorphic \\
\hline 0.829 & 20.725 & + & + & + & + & 1.00 & Monomorphic \\
\hline 0.848 & 19.781 & + & + & + & + & 1.00 & Monomorphic \\
\hline 0.882 & 18.199 & + & + & + & + & 1.00 & Monomorphic \\
\hline 0.932 & 16.100 & + & + & + & + & 1.00 & Monomorphic \\
\hline
\end{tabular}

Table 4.b. SDS-PAGE protein gel data analysis and the mean of band frequencies

\begin{tabular}{|l|c|c|c|c|l|c|}
\hline \multicolumn{4}{|c|}{ Lanes Polymorphism } & \multicolumn{4}{c|}{ Gel Polymorphism } \\
\hline & Egyptian & American & Rainbow & Black & \multicolumn{1}{c|}{ Monomorphic bands } & 16 \\
\hline Monomorphic bands & 16 & 16 & 16 & 16 & Polymorphic (without unique) & 3 \\
\hline Polymorphic bands (without unique) & 2 & 2 & 3 & 1 & Unique bands & 2 \\
\hline Unique bands & 1 & 1 & 0 & 0 & Polymorphic (with unique) & 5 \\
\hline Polymorphic bands (with unique) & 3 & 3 & 3 & 1 & Total number of bands & 21 \\
\hline Total number of bands & 19 & 19 & 19 & 17 & Polymorphism (\%) & $23.81 \%$ \\
\hline \multicolumn{4}{|c|}{ Mean of band frequency } & & 0.881 \\
\hline
\end{tabular}

of each band, data are represented in Figure 5 in comparison to the marker lane. These data indicate the elevated gene expression of the wild Egyptian variety above the other studied varieties (Balzotti et al. 2008; Berti et al. 2004)

\section{The relationship among the studied Quinoa Varieties}

During the current study, a clustering analysis was conducted on the protein banding patterns for the seed storage proteins of the studied quinoa varieties, which resulted from the SDS-PAGE technique. A relationship among the studied quinoa varieties using the method of UPGMA, an Unweighted pair group with the arithmetic mean, and employing the Jaccard's Coefficient was elucidated in Figure 6 and Table 5. The Wild Egyptian and the Rainbow quinoa varieties fell in one clade and were most related to each other by $90 \%$. Then, the black quinoa variety was more related to them, rather than the American quinoa variety. The similarities between the Black and American quinoa to the Wild Egyptian quinoa were 89.5\% and $81 \%$, respectively. At the same time, the similarities between the Rainbow quinoa to both the black and the American quinoa were 89.5\% and $90 \%$, respectively. Meanwhile, the similarity between the American and the Black quinoa was $80 \%$. Balzotti et al. (2008) performed a relationship analysis between quinoa and 49 other species and found that amaranth is the most related 


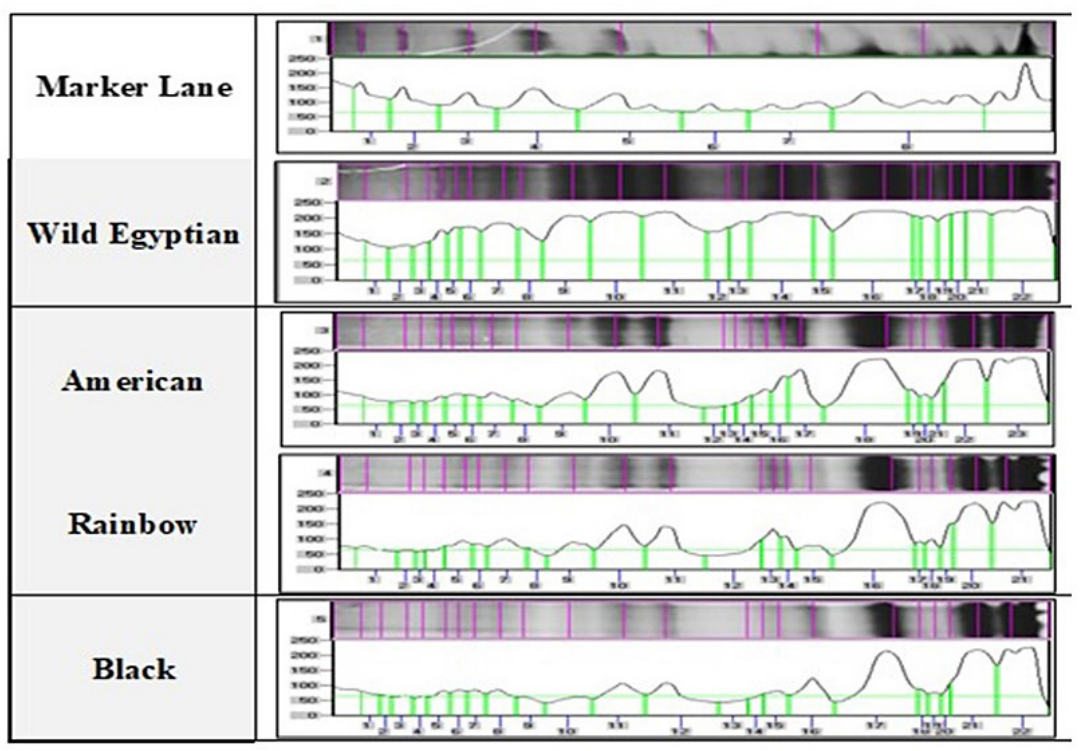

Figure 5. Lanes profiles for each of the studied quinoa varieties

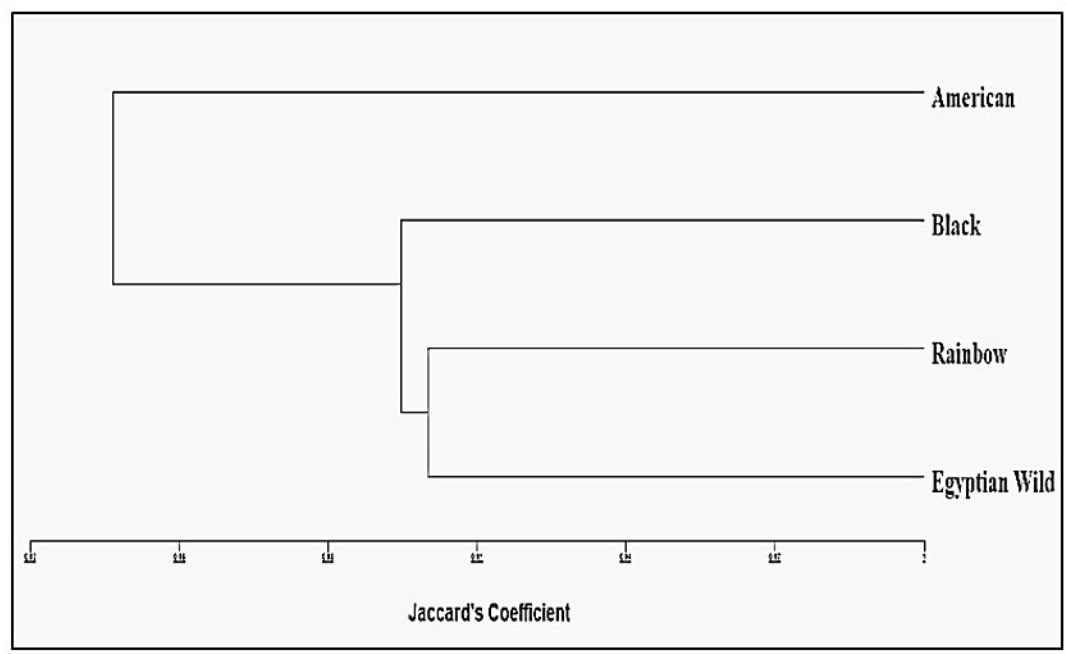

Figure 6. Dendrogram for the relationship among the studied quinoa varieties

Table 5. The similarity matrix among the studied quinoa varieties using UPGMA and Jaccard's Coefficient.

\begin{tabular}{|c|c|c|}
\hline Variety name & Origin & Seed color \\
\hline Wild Egyptian & Egypt & Pale yellow \\
\hline American & USA & Yellow \\
\hline Rainbow & Argentina & Red \\
\hline Black & USA & Black \\
\hline
\end{tabular}

to quinoa. Recently, Galindo-Luján et al. (2021) employed the capillary electrophoresis technique to classify the colored quinoa varieties, black, red, white, and royal white. Their classification resulted in the separation of the red quinoa from the three other quinoa varieties. However, they grouped both the white and royal white quinoa into one class from the remnant black quinoa, which was slightly different from them.

\section{CONCLUSIONS}

In various agro-climatic zones, both environmental and climatic factors affect the nutritional composition of quinoa crops, including total protein content and its composition of the amino. In the protein composition, a comparison among the studied quinoa cultivars from different geographical cultivation areas was done. 
Wild Egyptian quinoa seeds proved to contain an adequate percentage of the valuable protein content. The Wild Egyptian and the Rainbow quinoa varieties fell in one clade and were most related to each other. Further in-depth agronomic, nutritional, and molecular studies are necessary for the Wild Egyptian as a promising quinoa grain variety that can be cultivated widely in the arid lands for combating the food insecurity problem.

\section{Acknowledgment}

The authors wish to express their deep thanks of gratitude to Dr. Madyn M. Amr, Central Laboratory of Organic Agriculture (CLOA), Agricultural Research Center (ARC), and Prof. Abd El-Nasser Abou Rawash, Department of Environment and Organic Agriculture, Faculty of Agriculture, Al-Azhar University, for their support by providing the quinoa seed materials, and all of their sincere insights during this work.

\section{REFERENCES}

1. Abderrahim F., Huanatico E., Segura R., Arribas S., Gonzalez M.C., Condezo-Hoyos L. 2015. Physical features, phenolic compounds, betalains and total antioxidant capacity of coloured quinoa seeds (Chenopodium quinoa Willd.) from Peruvian Altiplano. Food Chemistry, 183, 83-90.

2. Al-Naggar A.M.M., Abd El-Salam R.M., Badran A.E.E., El-Moghazi M.M. 2017. Genotype and drought effects on morphological, physiological and yield traits of quinoa (Chenopodium quinoa Willd.). Asian Journal of Advances in Agricultural Research, 1-15.

3. Alvarez-Jubete L., Arendt E.K., Gallagher E. 2009. Nutritive value and chemical composition of pseudocereals as gluten-free ingredients. International Journal of Food Sciences and Nutrition, 60(4), 240-257.

4. Angeli V., Miguel Silva P., Crispim Massuela D., Khan M.W., Hamar A., Khajehei F., ... \& Piatti C. 2020. Quinoa (Chenopodium quinoa Willd.): An overview of the potentials of the "Golden Grain" and socio-economic and environmental aspects of its cultivation and marketization. Foods, 9(2), 216.

5. Balzotti M.R., Thornton J.N., Maughan P.J., McClellan D.A., Stevens M.R., Jellen E.N., ... \& Coleman C.E. 2008. Expression and evolutionary relationships of the Chenopodium quinoa $11 \mathrm{~S}$ seed storage protein gene. International Journal of Plant Sciences, 169(2), 281-291.

6. Berti C., Ballabio C., Restani P., Porrini M., Bonomi F., Iametti S. 2004. Immunochemical and molecular properties of proteins in Chenopodium quinoa. Cereal Chem., 81(2), 275-277.

7. Brinegar C., Goundan S. 1993. Isolation and characterization of chenopodin, the $11 \mathrm{~S}$ seed storage protein of quinoa (Chenopodium quinoa). Journal of Agricultural and Food Chemistry, 41(2), 182-185.

8. Carpenter W.C., Rai D.V., Samuel A.R., Höfner M.C. 1996. Comparison of a radioactive and nonradioactive method for sequencing foot and mouth disease virus isolates. Revue scientifique et technique (International Office of Epizootics), 15(3), 875-882.

9. Craine E.B., Murphy K.M. 2020. Seed composition and amino acid profiles for quinoa grown in Washington State. Frontiers in Nutrition, 7, 126.

10. Cruz C.D. 2013. Genes: a software package for analysis in experimental statistics and quantitative genetics. Acta Scientiarum. Agronomy, 35(3), 271-276.

11. D'ambrosio T., Amodio M.L., Pastore D., de Santis G., Colelli G. 2017. Chemical, physical, and sensorial characterization of fresh quinoa sprouts (Chenopodium quinoa Willd.) and effects of modified atmosphere packaging on quality during cold storage. Food Packaging and Shelf Life, 14, 52-58.

12. Encina-Zelada C., Cadavez V., Pereda J., GómezPando L., Salvá-Ruíz B., Teixeira J.A., ... \& Gonzales-Barron U. 2017. Estimation of composition of quinoa (Chenopodium quinoa Willd.) grains by Near-Infrared Transmission spectroscopy. LWTFood Science and Technology, 79, 126-134.

13. Filho A.M.M., Pirozi M.R., Borges J.T.D.S., Pinheiro Sant'Ana H.M., Chaves J.B.P., Coimbra J.S.D.R. 2017. Quinoa: nutritional, functional, and antinutritional aspects. Critical Reviews in Food Science and Nutrition, 57(8), 1618-1630.

14. Franzin S.M., Menezes N.L.D., Garcia D.C., Wrasse C.F. 2004. Métodos para avaliação do potencial fisiológico de sementes de alface. Revista Brasileira de Sementes, 26, 63-69.

15. Galindo-Luján R., Pont L., Sanz-Nebot V., Benavente F. 2021. Classification of quinoa varieties based on protein fingerprinting by capillary electrophoresis with ultraviolet absorption diode array detection and advanced chemometrics. Food Chemistry, 341, 128207.

16. González J.A., Konishi Y., Bruno M., Valoy M., Prao F.E. 2012. Interrelationships among seed yield, total protein and amino acid composition of ten quinoa (Chenopodium quinoa) cultivars from two different agroecological regions. Journal of the Science of Food and Agriculture, 92(6), 1222-1229.

17. Granda L., Rosero A., Benešová K., Pluháčková H., Neuwirthová J., Cerkal R. 2018. Content of selected vitamins and antioxidants in colored and nonpigmented varieties of quinoa, barley, and wheat grains. Journal of Food Science, 83(10), 2439-2447. 
18. Jaccard P. 1908. Nouvelles recherches sur la distribution florale. Bull. Soc. Vaud. Sci. Nat., 44, 223-270

19. Roman V.J., den Toom L.A., Gamiz C.C., van der Pijl N., Visser R.G., van Loo E.N., van der Linden C.G. 2020. Differential responses to salt stress in ion dynamics, growth and seed yield of European quinoa varieties. Environmental and Experimental Botany, 177, 104146.

20. Kappes C., Arf O., Ferreira J.P., Portugal J.R., Alcalde A.M., Arf M.V., Vilela R.G. 2012. Qualidade fisiológica de sementes e crescimento de plântulas de feijoeiro, em função de aplicações de paraquat em précolheita. Pesquisa Agropecuária Tropical, 42, 9-18.

21. Laemmli U.K. 1970. Cleavage of structural proteins during the assembly of the head of bacteriophage T4. Nature, 227(5259), 680-685.

22. Latimer Jr G.W. 2016. Official methods of analysis of AOAC International $20^{\text {th }}$ edition, Appendix D, Guidelines for collaborative study procedures to validate characteristics of a method of analysis. Gaithersburg, MD, USA.

23. Marcos Filho J. 2015. Fisiologia de sementes de plantas cultivadas: Fealq. FEALQ, Piracicaba, Brazil.

24. Miranda M., Vega-Gálvez A., Uribe E., López J., Martínez E., Rodríguez M.J., ... \& Di Scala K. 2011. Physico-chemical analysis, antioxidant capacity and vitamins of six ecotypes of Chilean quinoa (Chenopodium quinoa Willd). Procedia Food Science, 1, 1439-1446.

25. Mota C., Santos M., Mauro R., Samman N., Matos A.S., Torres D., Castanheira I. 2016. Protein content and amino acids profile of pseudocereals. Food chemistry, 193, 55-61.

26. Nowak V., Du J., Charbonnier U.R. 2016. Assessment of the nutritional composition of quinoa (Chenopodium quinoa Willd.). Food Chemistry, 193, 47-54.

27. Panuccio M.R., Jacobsen S.E., Akhtar S.S., Muscolo, A. 2014. Effect of saline water on seed germination and early seedling growth of the halophyte quinoa. AOB Plants, 6.

28. Piñuel L., Boeri P., Zubillaga F., Barrio D.A., Torreta J., Cruz A., ... \& Carrillo W. 2019. Production of white, red and black quinoa (Chenopodium quinoa Willd var. Real) protein isolates and its hydrolysates in germinated and non-germinated quinoa samples and antioxidant activity evaluation. Plants, 8(8), 257.

29. Qureshi A.S., Dabo A.W. 2020. Evaluating growth and yield parameters of five quinoa (Chenopodium quinoa W.) genotypes under different salt stress conditions. J. Agric. Sci., 12, 128.

30. Rodríguez S.D., López-Fernández M.P., Maldonado S., Buera M.P. 2019. Evidence on the discrimination of quinoa grains with a combination of FT-MIR and
FT-NIR spectroscopy. Journal of Food Science and Technology, 56(10), 4457-4464.

31. dos Santos C.A., da Silva N.V., Siqueira Walter L., da Silva E.C.A., Custódio Nogueira R.J.M. 2016. Germinação de sementes de duas espécies da caatinga sob déficit hídrico e salinidade. Brazilian Journal of Forest Research/Pesquisa Florestal Brasileira, 36(87).

32. Santos E.L.D., Póla J.N., Barros A.S.D.R., Prete C.E.C. 2007. Qualidade fisiológica e composição química das sementes de soja com variação na cor do tegumento. Revista Brasileira de Sementes, $29,20-26$.

33. Sigstad E.E., Prado F.E. 1999. A microcalorimetric study of Chenopodium quinoa Willd. seed germination. Thermochimica Acta, 326(1-2), 159-164.

34. Sobota A., Świeca M., Gęsiński K., Wirkijowska A., Bochnak J. 2020. Yellow-coated quinoa (Chenopodium quinoa Willd)-physicochemical, nutritional, and antioxidant properties. Journal of the Science of Food and Agriculture, 100(5), 2035-2042.

35. Song J., Yan Y., Wang X., Li X., Chen Y., Li L., Li W. 2021. Characterization of fatty acids, amino acids and organic acids in three colored quinoas based on untargeted and targeted metabolomics. LWT, 140, 110690.

36. Spehar C.R. 2007. Quinoa: alternativa para a diversificação agrícola e alimentar. Planaltina: Embrapa Cerrados, 1.

37. Taha M.G., Yossif H.M., El- Danasoury M.M., Salem R.E., Abd El-Hakim A.F. 2016. Biochemical studies of pathogenesis -related proteins in wheat plants as affected by chemical inducers treatments. Al-Azhar J. Agric. Res. 26, 74-88.

38. Thanapornpoonpong S.N., Vearasilp S., Pawelzik E., Gorinstein S. 2008. Influence of various nitrogen applications on protein and amino acid profiles of amaranth and quinoa. Journal of Agricultural and Food Chemistry, 56(23), 11464-70.

39. Vega-Gálvez A., Miranda M., Vergara J., Uribe E., Puente L., Martínez E.A. 2010. Nutrition facts and functional potential of quinoa (Chenopodium quinoa willd.), an ancient Andean grain: a review. Journal of the Science of Food and Agriculture, 90(15), 2541-7.

40. Vilcacundo R., Hernández-Ledesma B. 2017. Nutritional and biological value of quinoa (Chenopodium quinoa Willd.). Current Opinion in Food Science, 14, 1-6.

41. Wu Q., Bai X., Wu X., Xiang D., Wan Y., Luo Y., Shi X., Li Q., Zhao J., Qin P., Yang X. 2020. Transcriptome profiling identifies transcription factors and key homologs involved in seed dormancy and germination regulation of Chenopodium quinoa. Plant Physiology and Biochemistry, 151, 443-56. 